\title{
Sweeping practices, perceptions and knowledge about occupational safety and health hazards of street sweepers in Dhaka city, Bangladesh: a qualitative inquiry
}

\author{
Ashraful Kabir ${ }^{1 *}$, Nadia Farhana ${ }^{2}$, Farzana Akter ${ }^{3}$, Shahana Jesmin ${ }^{4}$, Ahsan Ali ${ }^{5}$
}

\begin{abstract}
${ }^{1}$ Research Coordinator, Dustya Shashthya Kendra, Dhaka, Bangladesh
${ }^{2}$ Student, Department of Political Science, Eden Mohila College, Dhaka, Bangladesh

${ }^{3}$ Student, Department of Anthropology, Jahangirnagar Univertity, Savar, Dhaka, Bangladesh

${ }^{4}$ Medical Officer, Department of Paediatrics, Dhaka Medical College, Dhaka, Bangladesh

${ }^{5}$ Professor, Department of Anthropology, Dhaka University, Dhaka, Bangladesh
\end{abstract}

Received: 04 May 2015

Accepted: 07 June 2015

*Correspondence:

Ashraful Kabir,

E-mail: ashraful262@yahoo.com

Copyright: (C) the author(s), publisher and licensee Medip Academy. This is an open-access article distributed under the terms of the Creative Commons Attribution Non-Commercial License, which permits unrestricted non-commercial use, distribution, and reproduction in any medium, provided the original work is properly cited.

\section{ABSTRACT}

Background: Street sweepers play important roles for keeping the cities clean. Their works entail removing of debris from streets, collecting solid waste, disposing and recycling waste material. Consequently, they have higher chances to be exposed to numerous risk factors; therefore, their occupational safety and health hazard became crucial. There is little evidence about the sweeping practices, perceptions and knowledge on their occupational safety and health hazards. The objective of the study is to explore current sweeping practices, perceived risk and the level of knowledge of a group of street sweepers of Dhaka city.

Methods: An explorative qualitative research design was used. We conducted 15 IDIs, 8 KIIs and 5 FGDs with Telegu street sweepers, community and religious leaders and NGO workers in two different sweeper colonies in Dhaka City.

Results: Due to the manual handling process, the street sweepers are often exposed to a variety of risks factors exhaust fumes, extreme noise, toxic substances and dust particles. Frequent infections and injuries were reported commonly as they lack basic safety equipment's during works. Low perceived health hazards were prevalent. Strong faith-based explanations were found to rationalize possible health hazards.

Conclusions: A number of socio-economic factors influence the level of knowledge and risk perception. Interventions on awareness building program coupled with behaviour change counselling (BCC) activities would be appropriate to address the lack of knowledge on health hazards and low risks perception.

Keywords: Health hazard, Occupational safety, Perception and knowledge, Qualitative approach, Street sweepers

\section{INTRODUCTION}

Work related safety and health hazards are a major public health concern worldwide and are under-researched especially in low and middle income countries. ${ }^{1}$ According to the World Health Organization (WHO), 58 percent of the global population spends one-third of their time at work during adulthood. ${ }^{2}$ Therefore, the issue of work related safety has gathered increasing attention in the public health domain. The prevalence and incidence of injuries and deaths have gradually risen over the years - approximately 0.9-2.3 million work related deaths were estimated by the International Labour Organization (ILO) worldwide in $2003 .^{3}$ Furthermore, the ILO reported in the same year that there were an estimated 358,000 fatal occupational accidents, 337 million occupational accidents and 160 million occupational diseases worldwide. ${ }^{4}$ Higher prevalence of injuries and death were 
found among the urban population in low and middle income countries. ${ }^{5}$

In Bangladesh, the situation of work-related safety and health hazards is problematic and the risk of health hazards varies among different working groups. ${ }^{6}$ Street sweepers of Dhaka City are a working group who play an integral role in solid waste management and are exposed to a high number of risk factors during their works. Moreover, their occupational safety and health hazard has been crucial since they play important role for maintaining the hygiene and health of the city through their routine physical appearance at workplaces. The daily activities of street sweepers in Dhaka include removal of debris from streets, solid waste collection, disposal and recycling waste materials. ${ }^{7}$ Although the exact occupational risk factors are not known among Bangladeshi street sweepers, existing literatures show that sweeping activities in other countries are often require exposure to large amount of dust, bio-aerosol, volatile organic matter, airborne particulates, bacteria, noise, and ergonomic stress while working. ${ }^{8-12}$ The susceptibility to develop many occupational health problems increases throughout their lives. The usual sweeping practices, perceived occupational risk factors and level of knowledge about health safety of street sweepers in Dhaka are not known although the need for protection and promotion of health and safety at workplaces has been the focused in a number of policy documents, such as the WHO constitution, Alma Ata Declaration, and Health for All strategies. ${ }^{13-15}$ Therefore, better understanding of street sweepers' knowledge, perceptions concerning occupational safety and related health hazards has become crucial for designing appropriate programs for the overall improvement of their health condition. This study will explore current sweeping practice, perception the level of knowledge, of a group of street sweepers in Dhaka city.

\section{METHODS}

\section{Study context}

This study was conducted among two sweeper colonies of the Telegu community - Agargaon Public Works Department (PWD) sweeper Colony, and Gonoktuli sweeper colony both in Dhaka city. Colonies are settlements where street sweepers live together, either informally set up by private companies or through formal arrangements with the municipal government, and whether street sweepers live in the colonies dependents on whether they are formally or informally employed. The Telegu are a marginalized group of people from one of the lowest caste, which originally migrated from India several hundred years ago. While official statistics are not available about the exact number of sweepers in these colonies, secondary sources estimate that approximately 1000 families live in each colony. ${ }^{16}$ These families live in homes made of mostly bamboo, wood and choterbosta (sacks) in an unhygienic environment that faces frequent shortage of basic services and irregular supply of water, electricity and gas. There is pervasive insecurity due to the presence of crime and threats of eviction. The local mastan (thug/local muscleman), violence, crime, and illegal drug dealing are part of the everyday life in colonies. Poor sanitation leads to large volumes of dirt and garbage, bad odours. Lack of education and available information on public services combined with belief in traditional rituals and religious practice contribute to poor access and usage of health services. For example, when a household member falls ill, Telegu are more likely to manage the illness within the community and rely on traditional healers.

\section{Study sample and participants}

Purposive sampling was used to explore the level of knowledge, perception and current practices relating to occupational safety and health hazards among the Telegu street sweepers of Dhaka. Key informant interviews (KIIs) were conducted with community leaders, religious leaders, and NGO workers. In-depth interviews (IDIs) were conducted with male and female household members who were involved in sweeping activities. Additionally, focus group discussions (FGDs) were conducted to understand community perceptions and attitudes regarding the safety of their daily work and procedures that they maintained at work. A total of 15 IDIs, 5 FGDs and 8 KIIs were conducted. We also took paid some informal visit to observe their workplaces. The number of interviews was based on the principle of data saturation - stop conducting interviews while no new data or themes come.

\section{Data collection procedure}

The interviews were conducted in Bangla language - the mother language of both the researcher and the most of the respondents. However, in the case of elderly respondents a translator was hired as they speak Telegu. A flexible conversation guideline was followed containing a range of themes and topics related perceptions and practices of occupational safety and health hazards such as the use of safety equipment, level of knowledge about risks, health impacts, etc. On average, each interview took 45 to 60 minutes. We established good rapport with the respondents before starting conversation and described the purpose and large scale benefit of the study. After establishing good rapport, the researcher started conversation in a private location either inside or in front of the respondents' home. The conversation was recorded electronically, transcribed verbatim, and subsequently translated into English. In cases where further clarification and probing was required, follow up visits were made to capture the missing information. Detailed field notes were taken during the conversation and in some cases a local interpreter was used. 


\section{Data management and analysis}

We developed a list of codes, or key words, based on the analysis of textual data identifying the significant and/or meaningful statement in the text. ${ }^{17,18}$ Thereafter, we identified some codes in line with our research objectives. Once, all the interviews were coded, we looked for clusters consisting of several codes that could be termed as a theme or concept. We performed a triangulation of methods in order to ensure greater data validity utilizing IDIs, KIIs and FGDs. Finally, the descriptions of participant experiences were organized analytically in the findings.

\section{Ethical consideration}

The study was done as a partial fulfillment of a Master of Social Science (MSS) degree in Anthropology from Dhaka University. An informed consent form was developed and approved by the Dhaka University Department of Anthropology explaining the objective, importance, confidentiality, possible harm and benefit, participant's rights and source of further information or queries to potential respondents. We sought only verbal consent considering the hesitation of respondents to sign documents and low literacy rate. Amongst poor and illiterate households, asking for a signature or finger print is associated with entering contractual agreements or other official/taxation purposes, and therefore people are very hesitant to comply unless there is a high degree of trust.

\section{RESULTS}

As mentioned above, 15 in-depth interviews, 8 key informant interviews and 5 focus group discussions were conducted. Table 1 below summarizes the sociodemographic characteristics of interview respondents.

Median age of respondents is 28.77 years. Most respondents had no formal schooling $(73 \%)$ which indicates that the rate of literacy was extremely below from the national level $(57.7 \%)$. Only one woman had education above primary level, and the combined average number of years of school was 2.44. The majority of respondents $(73 \%)$ were engaged in street cleaning activities for Dhaka City Corporation or private organizations, while others were involved in day labor, leather processing and doing household activities in their own homes. Almost two-thirds $(73 \%)$ of participants live in a nuclear family. Nearly half (47 \%) of participants were Telegu, one third (33\%) Hindu and the rest had converted to Christianity.

\section{Current sweeping practice}

Our findings reveal that street sweepers manually handle a variety of waste - domestic, industrial, and commercial. Their work involves collecting, sweeping and dumping garbage on the streets every day. Due to the manual handling process, they are often exposed to a variety of risks - exhaust fumes, extreme noise, toxic substances and dust particles. All respondents were found to have direct physical exposure to risk elements as they lack any Personal Protective Equipment (PPE). However, a few (13\%) street sweepers reported wearing a uniform. As a result, cuts and other injuries were commonly reported during interviews and group discussions. One of the participants stated,

“We don't put on any glove, boot or mask during the work. We rarely put uniforms. ...of course, we cut our fingers or legs many times. It is natural to cut or be injured ourselves if we don't have any protective measures at our work" (A female participant from IDI)

Table 1: Socio-demographic background of indepthinterview respondents $(\mathrm{N}=15)$.

\begin{tabular}{|c|c|c|}
\hline Socio-demographic characteristics & $\mathbf{N}$ & $\%$ \\
\hline $\begin{array}{l}\text { Median of age of the respondents } \\
\text { (yr) }\end{array}$ & & \multirow[t]{2}{*}{28.77} \\
\hline \multicolumn{2}{|l|}{ Education } & \\
\hline $1-5 \mathrm{yr}$ & 3 & $20 \%$ \\
\hline $6-10 \mathrm{yr}$ & 1 & $7 \%$ \\
\hline No formal schooling & \multirow[b]{2}{*}{11} & $73 \%$ \\
\hline Mean schooling (yr) & & 2.44 \\
\hline \multicolumn{3}{|l|}{ Occupation } \\
\hline Street Cleaning & 11 & $73 \%$ \\
\hline Leather worker & 1 & $7 \%$ \\
\hline House wife & 2 & $13 \%$ \\
\hline Other & 1 & $7 \%$ \\
\hline \multicolumn{3}{|l|}{ Sex } \\
\hline Male & 10 & $67 \%$ \\
\hline Female & 5 & $33 \%$ \\
\hline \multicolumn{3}{|l|}{ Marital Status } \\
\hline Married & 11 & $73 \%$ \\
\hline Unmarried & 3 & $20 \%$ \\
\hline Divorced & 1 & $7 \%$ \\
\hline \multicolumn{3}{|l|}{ Family Type } \\
\hline Extended & 4 & $27 \%$ \\
\hline Nuclear & 11 & $73 \%$ \\
\hline \multicolumn{3}{|l|}{ Religion } \\
\hline Telegu & 7 & $47 \%$ \\
\hline Hindu & 5 & $33 \%$ \\
\hline Converted Christian & 3 & $20 \%$ \\
\hline $\mathbf{N}$ & 15 & \\
\hline
\end{tabular}

Another participant explained the situation,

\footnotetext{
"While we deal with broken glass and discarded sharp objects, it is normal to have cut or bleeding due to having no protective measures. ...Many times I had cut my fingers resulted in heavy bleeding." (A male participant from IDI)
} 
More than one third of participants (40\%) reported that they had developed serious infections due to cuts by either medical equipment or other sharp objects. They reported that sharp objects were often found in and around dust-bins and caused physical injuries during their work.

One of the participants explained the situation,

"Developing serious infections is not unusual as our occupation expose us to such situation throughout the life. We always deal with danger as we don't take any safety measures. We expose ourselves to danger with empty hands" (A male participant from FGD)

Almost all the participants admitted that they had far more exposure to bad odours at work specially while they collect and sweep garbage from large collection bins or dumpsters since they do not wear masks. They reported that bad odours often induced vomit and sometimes increase loss of appetite. During the monsoon the situation worsens, as the frequent and continuous rainfall causes acute bad odour. One of the participants said,

"I smell a strong bad odour especially during the monsoon. The smell is very strong; sometimes remain intolerable. I feel weak and loose appetite. These exposures also lose my patience to co-workers. ...we often get irritated with very small issue" (A female participant from IDI)

The incidence of fatal and serious road accidents is also high due to the increased risk of being hit by vehicles while working on the busy and narrow streets. The participants reported that they begin their work early in the morning and continued till they finish, no matter the time. During their work, they come into close contact with a variety of heavy and light motor vehicle on the street, often suddenly and at high speeds. The likelihood of motor vehicle accidents increases the risk of injuries and death on the road side. One of the participants stated,

"I was hit by a pick-up van while I was sweeping in a narrow street at Mohammadpur (a locality in Dhaka city). It happened very suddenly. I did not understand the fact that a vehicle was coming at me with high speed. The vehicle hit my back. Luckily I survived as it was a light motor vehicle. Nevertheless, it was a high cost for me and my family as I took a month long bed rest with huge medical expense" (A female participant from IDI)

Almost all the participants reported routine exposure to dust particle at their work. Participants reported that they sweep street waste, which stirs up dust particles, wearing no mask. This manual way of waste removal exposes them to a situation where they inhale dust particles frequently, using brooms made locally of coconut straw for brushing and collecting debris on the street.
Sweeping creates a large concentration of dust, which the street sweepers then inhale while working. One of the participants stated,

"While I sweep the street through manual brushing, it produces a heavy dark dust cycle around me. I feel that it creates difficult breathing. The concentration often gets worst during the winter (when there is no rain). What can we do except inhaling pure dust?" (A male participant from IDI)

\section{Another participant reported,}

"During the winter, I cannot see the person or object in front of me while I sweep by broom. This time the concentration of dust get high due to no rainfall. ...We have no option to avoid it because it is our job. We earn through this condition" (A female participant from FGD)

We also found that most of the street sweepers remove street dust wearing no musk during our observation, increasing the risk of being infected by a number of air borne diseases. Furthermore, a number of participants from different sources reported to have respiratory and skin problems. One of key informants said,

"If you examine their health you will find many street sweepers are living with chronic obstructive pulmonary disease, bronchioles, bacterial pneumonia, pulmonary embolism, breathing difficulties etc. ...the reason is that they are frequently exposed to the pathogens that are transmitted through air." (A key informant from KII)

Sweepers' perception and level of knowledge on occupational safety and health hazards: We found a variety of perceptions regarding occupational safety and health hazards among participants. However, the majority appeared to have low risk perceptions regarding the chances of being infected or injured at work. More than one third of the participants believed that infection, injuries, accident and death can happen to anyone, at any time, and anywhere, thus normalizing the perception of injury and health problems. One of the participants stated,

"An accident or injury can happen to anyone at any place. ...Therefore, it does not necessarily mean that the sweepers will have higher chance to have infection or injuries. ...Many people who are not engaged with sweeping also get injured or infected" (A female participant from IDI)

Some of the participants had a strong belief that the risk of getting infected or injured depends on their faith. Therefore, they could not escape these problems if it would have been fixed by the almighty. Many households have been engaged in the sweeping activities for several generations; nevertheless, few had experienced any death that they attributed to the work. Additionally, some believed that they had developed a natural defense system in their body through prolonged exposure to such 
infectious agents, and that naturally they have a stronger immunity than non-sweepers. One of the participants explained the fact,

"I have been working with garbage, bad odour. It is not unusual for me and I don't feel bad to be exposed to such condition. ...however, you (the interviewer) might feel horrible while come across. ...because you are not used to take this bad smell" (A female participant from IDI)

However, more than two thirds of participants reported that such unprotected working conditions might increase the risk of getting infection or health hazards at work. Prolonged exposure to unhygienic conditions might cause a number of health problems. Breathing difficulties, skin rash, stomach ache, jaundice, fever, gastric problems, and eye irritation were reported as the most common health problems due to the street sweeping. Almost one third of participants reported that the high concentration of dust in and around their workplace might be the cause of respiratory problems. One of the participants explained that fact,

"The street sweepers had more chances to have respiratory problem as they work in high concentration of dust particle at work. ...Therefore continually inhale large quantity of dust every day. Due the prolong exposure to dust particle they might be susceptible to respiratory illness" (A male participant from FGD)

Another participant were explaining the fact,

"In Dhaka city, the most generous thing in winter is the high concentration dust particle. Dust particle cause respiratory problem as it enter into the body through inhalation." (A female participant from IDI)

The participants also reported that unsafe working conditions might result in developing a range of diseases and increase vulnerability to illnesses. However, they reported that the occupational hazard might be minimised through the introduction of personal protective equipment at work. Most of the participants believed that wearing hand gloves, mask and boot might contribute to the reduction of health hazard significantly. One of the participants mentioned,

"Wearing globes mask and boot may reduce the susceptibilities to health risk. If we put on mask, it will prevent dust inhalation. ...boot will protect legs and finger from sharp object"

However, some of the participants reported that the sweeper might feel uneasy to wear personal protective equipment. They might be irritated feeling at these items as they were not used to using it.

\section{DISCUSSION}

The findings of this study reveal that occupational safety and health hazards were not a major concern among street sweepers in Dhaka city. Street sweepers seemed less aware of the personal hygiene and precautionary measure. Similar observation was made by the work of Punder in Nepal. ${ }^{19}$ The broader socio-economical determinants of health might construct such perception as low literacy rate, ignorance, poor income are predominantly higher among the street sweeper communities. Additionally, the lack of availability of protective equipment and monitoring of health status limit the usage of PPE. Building awareness could decrease exposure to health hazards.

The street sweepers perceive their work to be less hazardous than the actual likelihood of work-related injuries and illnesses during conversations. Street sweeping and other waste picking activities do not involve life-threatening hazards according to the perception of workers. Numerous previous studies have found that the extent of health hazards or risk was perceived in accordance with the likelihood of occurrences of accidents or injuries. ${ }^{20,21}$ In other words, the danger of any occupation was linked to the experiences of workers involved in the particular occupation. The perceptions of occupational safety and health hazards among street sweepers might be influenced by the severity of health problems and the understanding of links between certain environmental factors and health problems. Our findings reveal that the experience of fatalities as a result street sweeping was low, and therefore the perception of risk was low among workers. However, a portion of street sweepers perceive that their work does expose them to a number of health risk as personal safety measures at work are lacking. Despite perceived negative impacts of a lack of occupational safety and health hazards, the street sweepers have few options for minimizing the risk. Our findings report that the majority of waste pickers are from households with generations of street sweepers, and therefore there a few chances of avoiding these risks.

The sweepers come from a disadvantaged community in a society where they feel significant social exclusion and internally adopt beliefs of inferiority. ${ }^{22}$ The low social position of street sweepers might contribute to the construction of their low risk perception at work. The perception of occupation risk and safety are largely determined by the position and rank of the individual and/or group within given situation. ${ }^{23-25}$ Low social status diminishes the scope of high risk perception in the street sweeper community regarding the occupational safety and health risk. Since street sweepers do not view themselves as having a large amount of personal value, they remain less concerned about their own health and safety. Due to the lack of adequate concern from the government, health and safety remain as constant threats and as a result street sweepers continue to be exposed to 
occupational risk. The perception of risk is not always rationalized by the assessment of risk by the actors or the working condition of the individual or group. ${ }^{26}$ Silva and colleagues suggest that an individual's sense of risk are determined by the "safety climate," meaning that an individual working in an unsafe climate seem to have less internal attribution. ${ }^{26,27}$ The lack of necessary measures taken by the employers or managers acerbates the risk of occupational health hazards. Street sweepers have rationalized the amount of occupational and health hazards that they are exposed to as a result of their relatively low social position.

In our study, we looked at two dimensions of knowledge regarding occupational safety and health hazards. First, we explored the level of knowledge and awareness of street sweepers regarding the health risks related to their work. Second, what are the possible ways to minimize the health hazards exposed to at work? Our findings reveal that most of the participants are unaware regarding occupational safety and health risk, possible route of transmissions of infections or diseases, and potential mechanisms for minimizing the negative health impacts of occupational hazards at their work place. Their knowledge and awareness comes from multiple sources including health promotion activities, exposure to media and awareness campaigns, dynamic communication with knowledgeable people and organizations, and intracommunity relations. ${ }^{28}$ The street sweepers have limited formal schooling. The exposure to health promotion activities either by employers or other agencies is limited with regards to health risk and safety matters. A study on childhood tuberculosis, in Bangladesh by Fahmidul et al. found that the level of knowledge and health safety is impacted by socio-cultural and economic factors including occupation and the level of standard of the community. ${ }^{29}$ The level of awareness on the transmission of occupation related infection or diseases of street sweepers is therefore low as a result of limited or no access to health information.

\section{CONCLUSION}

In this study, we investigated the practices, perceptions and level of knowledge of street sweepers in Dhaka city with regards to work related safety and health risks. Our findings highlight that the majority of street sweepers perceive that work related health risks are prevalent though few safety measures are taken in practice. Most street sweepers have little knowledge about the possible ways of transmitting infections and diseases. Lower socio-cultural and economic conditions of the Telegu community contribute to the construction of low risk perceptions regarding the probability of infections and susceptibility to diseases. An awareness building program coupled with behaviour change counselling (BCC) activities would be an appropriate intervention to address the lack of knowledge on health hazards and low risks perception. An education program may be successful for improving the level of knowledge of best practices of safely managing municipal waste. The employer should be included in intervention design as they play an important role to improve overall condition of solid waste management and workplace safety.

\section{ACKNOWLEDGEMENTS}

The authors would like to acknowledge with gratitude to the Department of Population Science, Dhaka University for providing UNFPA grant for master's thesis. The authors are also grateful to the study participants who gave their valuable time for interviews. They express their gratitude to the community leaders who expand their cooperation for community access.

Funding: Department of Population Science, Dhaka University for providing UNFPA grant for master's thesis

Conflict of interest: All authors declared that they have no conflict of interest

Ethical approval: This research was approved by the department of anthropology, Dhaka University

\section{REFERENCES}

1. Bleck D, Wettberg W. Waste collection in developing countries--tackling occupational safety and health hazards at their source. Waste Manag. 2012;32(11):2009-17.

2. Global Strategy on Occupational Health for All: The Way to Health at Work. Geneve, Switzerland: World Health Organization; 1995.

3. WHO. The joint WHO-ILO-UNIAIDS policy guidelines on improving health worker's access to HIV and TB prevention, treatment, care and support services (A GUIDELINE NOTE). Geneva, Switzerland; 2010.

4. Niu S. Ergonomics and occupational safety and health: an ILO perspective. Appl Ergon. 2010;41(6):744-53.

5. World Health Organization. Our cities, our health, our future: Acting on social determinants for health equity in urban settings. Japan: World Health Organization; 2008.

6. Akram W. Occupational Health, Safety and Extreme Poverty: A Qualitative Perspective from Bangladesh. Int $\mathbf{J}$ Occup Safety and Health. 2015;4(1):41-50.

7. Amin AN. The Informal Sector's Role in Urban Environmental Management. International Review for Environmentai Strategies 2005;5(2):511-30.

8. Krajewski JA, Tarkowski S, Cyprowski M, Szarapinska-Kwaszewska J, Dudkiewicz B. Occupational exposure to organic dust associated with municipal waste collection and management. Int J Occup Med Environ Health. 2002;15(3):289301.

9. Sigsgaard T. Health hazards to waste management workers in Denmark. Schriftenr Ver Wasser Boden Lufthyg. 1999;104:563-8. 
10. da Silveira EA, Robazzi ML, Luis MA. Street cleaners: occupational accidents in the city of Ribeirao Preto, State of Sao Paulo, Brazil. Rev Lat Am Enfermagem. 1998;6(1):71-9.

11. Anwar SK, Mehmood N, Nasim N, Khurshid M, Khurshid B. Sweeper's lung disease: a crosssectional study of an overlooked illness among sweepers of Pakistan. Int J Chron Obstruct Pulmon Dis. 2013;8:193-7.

12. Vanegas Useche LV, Wahab MM, Parker GA. Effectiveness of gutter brushes in removing street sweeping waste. Waste Manag. 2010;30(2):174-84.

13. WHO. Declaration on Workers Health. Stresa, Italy: WHO Collaborating Centres for Occupational Health; 2006.

14. World Health Organization. Declaration of AlmaAta: International Conference on Primary Health Care, Alma-Ata, USSR, 6-12 September 1978. World Health Organization; 1978.

15. World Health Organization. Constitution of the World Health Organization (Forty-fifth edition). Geneve: WHO; 2006.

16. The Life and Days of (Dalit) Sweepers in Bangladesh. The Daily Star 2006.

17. Guest G, Bunce A, Johnson L. How many interviews are enough? Experiments in data saturation and variability. Field Methods. 2006;18(1):59-82.

18. Tashakkori A, Teddlie C. Handbook of Mixed Methods in Social \& Behavioral Research. Thousand Oaks: Sage; 2013.

19. Pandey R. sweepers and scavengers in third World cities: A study on occupational health problems of sweepers and scavengers of Kathmandu, Nepal University of Oslo; 2004.

20. Gyekye SA. Causal attributions of Ghanaian industrial workers for accident occurrence: miners and non-miners perspective. J Safety Res. 2003;34(5):533-8.

21. Harrell WA. Perceived risk of occupational injury: control over pace of work and blue-collar versus white-collar work. Percept Mot Skills. 1990;70(32):1351-9.

22. Patwary MA. Domes and the Dead: An Example of Extreme Fatalism among Mortuary Workers in Bangladesh. Kaleidoscope: The Interdisciplinary Postgraduate Journal of Durham University's Institute of Advanced Study. 2010;10-8.

23. Hunt C. Child waste pickers in India: the occupation and its health risks. Environment and Urbanization 1996;8(2):111-7.

24. Nkonge NA, Mayabi OA, Kithinji J, Magambo KJ. Knowledge, attitude and practice of health-care waste management and associated health risks in the two teaching and referral hospitals in Kenya. J Community Health. 2012;37(6):1172-7.

25. C F. Social aspects of solid waste recovery in asian cities. Environmental Sanitation Reviews Series 1990;(30).

26. Patwary AM, O'Hare WT, Sarker MH. Occupational accident: An example of fatalistic beliefs among medical waste workers in Bangladesh. Safety Sci. 2012;50:76-82.

27. Silva Seal. OSCl: An Organizational and Safety Climate Inventory. Safety Science. 2004;(42):20520.

28. Muela SH et al. The PASS-model: a model for guiding health-seeking behavior and access to care research. Malaria Reports. 2012;2:e3.

29. Haque AF, Khan A-Z, Lutlunnahar B, Mukti IJ, Islam $\mathrm{T}$, Chakma $\mathrm{S}$, et al. Assessment of Bangladeshi mothers' knowledge and awareness on childhood tuberculosis: A cross sectional study. Science Journal of Public Health. 2014;309-5.

Cite this article as: Kabir A, Farhana N, Akter F, Jesmin S, Ali A. Sweeping practices, perceptions and knowledge about occupational safety and health hazards of street sweepers in Dhaka city, Bangladesh: a qualitative inquiry. $2015 \mathrm{Aug} ; 2(3): 237-43$. 